\title{
Light-Driven Hydrogen Production from Photosystem I-Catalyst Hybrids
}

Lisa M Utschig, Sarah R Soltau, David M Tiede

Chemical Sciences and Engineering Division, Argonne National Laboratory, Argonne, IL 60439

Corresponding Author:

Lisa M. Utschig

CSE Division/Bldg. 241/B265

Argonne National Laboratory

9700 S. Cass Ave.

Argonne, IL 60439

01116302523544

(utschig@anl.gov) 


\begin{abstract}
Solar energy conversion of water into environmentally clean fuels, such as hydrogen, offers one of the best long-term solutions for meeting future global energy needs. In photosynthesis, high quantum yield charge separation is achieved by a series of rapid, photoinitiated electron transfer steps that take place in proteins called reaction centers (RCs). Of current interest are new strategies that couple RC photochemistry to the direct synthesis of energy-rich molecules, offering opportunities to more directly tune the products of photosynthesis and potentially to increase solar energy conversion capacity. Innovative designs link RC photochemistry with synthetic molecular catalysts to create earth abundant biohybrid complexes that use light to rapidly produce hydrogen from water.
\end{abstract}




\section{Introduction}

Solar energy is an important source of renewable, non-carbon energy.[1,2] An abundant resource, the sun provides more energy to the earth in one hour than humans consume in an entire year. Sunlight, however, is highly diffuse and intermittent, and thus the large scale utilization of solar energy requires its cost-effective, long-term storage. To address these needs, current solar energy research involves developing practical schemes for capturing, converting, and storing the sun's energy in the form of high-energy chemical bonds of molecules as a reduced fuel, or "solar fuel", such as hydrogen, methanol, or methane. The direct production of hydrogen using sunlight and water is a particularly attractive approach to sustainable energy production. Unlike carbon-based fossil fuels that produce environmentally harmful $\mathrm{CO}_{2}$, hydrogen is a clean fuel because, upon burning to release the energy in its chemical bond (140 $\mathrm{MJ} / \mathrm{kg}$ ), water is produced. Recent advances in solar fuel research involve using Nature's photosynthetic chemistry for direct solar hydrogen production.

For over a billion years, Nature has optimized the photosynthetic machinery that converts light energy into chemical energy. [3,4] The primary energy conversion reactions occur in integral membrane proteins called reaction centers ( $\mathrm{RCs}$ ) and involve rapid, sequential electron transfers resulting in efficient charge separation across the membrane, establishing an electrochemical potential. Photosynthesis occurs in two main classes of organisms: photosynthetic bacteria that do not evolve oxygen, and organisms such as green plants that perform oxygen evolution. The first X-ray crystal structures of the RC from purple photosynthetic bacteria were determined in the mid-1980's.[5,6] The bacterial RC structure reveals key design features for photosynthetic photochemistry and remains an excellent "model" system for spectroscopic exploration of basic RC structure and function relationships.[7] Light-induced electron transfer in the bacterial RC 
results in directional proton transport across the membrane, establishing a $\mathrm{pH}$ gradient that drives ATP synthesis.[3] Higher plants, green algae, and cyanobacteria use two types of large RCs in tandem to convert and store solar energy as chemical free energy. Photosystem II (PSII) [8] carries out light-driven oxidation of water whereas Photosystem I (PSI) [9] catalyzes transmembrane light-driven electron transfer between small electron carrier proteins. These electrons are then used to produce a more stable reductant NADPH, the biological equivalent of $\mathrm{H}_{2}$, which is a source of reducing equivalents for Calvin cycle $\mathrm{CO}_{2}$ fixation and final chemical energy storage. However, kinetic limitations for $\mathrm{CO}_{2}$ fixation and electron transfer through the photosynthetic electron transfer chain causes saturation of solar energy capture with insolation that is approximately $20 \%$ of mid-day sun. $[10 \bullet \bullet, 11]$ This excess light-harvesting capacity is one of the sources for loss of solar energy conversion efficiency in photosynthesis.[10••-13]

PSI's built in light-harvesting and charge separation capabilities make it an attractive candidate for solar fuel production. [14] Multiple carotenoids and chlorophylls encircle the protein periphery, together acting as an efficient antenna system for light capture. The captured excitation energy is transferred to the center of the protein complex where the primary electron donor of PSI, P700, becomes oxidized with concurrent electron transfers through a cascade of donor/acceptor molecules terminating in electron transfer to a $[4 \mathrm{Fe}-4 \mathrm{~S}]$ cluster called $\mathrm{F}_{\mathrm{B}}$. The quantum yield of PSI approaches 1, thus nearly every photon captured is converted to the chargeseparated state $\mathrm{P} 700^{+} \mathrm{F}_{\mathrm{B}}{ }^{-}$. The $\mathrm{P} 700^{+} \mathrm{F}_{\mathrm{B}}{ }^{-}$state is long-lived, $\sim 60 \mathrm{~ms}$, and the $\mathrm{F}_{\mathrm{B}}$ cluster has a standard midpoint potential of $-580 \mathrm{mV}$ (vs NHE, $\mathrm{pH}$ independent) that provides sufficient driving force to power alternative reduction chemistry, including the reduction of protons to $\mathrm{H}_{2}$. In contrast, both bacterial RC and PSII have terminal quinone acceptors $\left(\mathrm{E}_{\mathrm{m}} \sim 0 \mathrm{mV}\right)$ that provide no driving force for proton reduction. 
Engineering PSI to produce $\mathrm{H}_{2}$ either as a replacement or in addition to NADPH requires redirection of PSI electron transfer to a catalytic component for reductive proton-coupled chemistry (Figure 1). Photosynthetic hydrogen would provide a fuels product with higher energy storage $\left(\mathrm{E}_{\mathrm{m}}, \mathrm{pH} 6.3=-370 \mathrm{mV}\right)$ than $\mathrm{NADPH}\left(\mathrm{E}_{\mathrm{m}}, \mathrm{pH} 6.3=-300 \mathrm{mV}\right)$ and one that potentially could be developed to avoid down-regulation that occurs at high light intensities. PSI's photogenerated electrons have been successfully coupled to hydrogenase enzymes and platinum catalyst systems. The use of abiotic catalysts for photosynthetic hydrogen production is of interest since they provide an opportunity to avoid the oxygen liability of hydrogenases. The overall focus of this review highlights recent strategies inspired by artificial photosynthetic systems that link PSI photochemical charge separation to $\mathrm{H}_{2}$-evolution via synthetic molecular complexes. These new biohybrid designs are composed of earth-abundant materials, work in water, and have high catalytic activity thereby directly addressing several key challenges to making solar fuels a viable energy source.

\section{Photosystem I-Hydrogenase Hybrids}

One earth-abundant PSI-hybrid strategy includes using hydrogenases, enzymes that catalyze the reversible interconversion of $\mathrm{H}_{2}$ to protons and electrons. Two types of hydrogenases (classified by the metal composition of their respective active site metal centers) have been linked to PSI, each with inherent advantages and disadvantages. [15,16] [FeFe]-hydrogenases preferentially catalyze proton reduction and can evolve $\mathrm{H}_{2}$ at high rates $\left(10,000 \mathrm{~s}^{-1}\right)$, but these enzymes are highly sensitive to $\mathrm{O}_{2}$, which can irreversibly damage the active site. [NiFe]-hydrogenases are less sensitive to $\mathrm{O}_{2}$ than [FeFe]-hydrogenase, but are more commonly associated with $\mathrm{H}_{2}$ oxidation under physiological conditions.[17•] Linked PSI-[NiFe]-hydrogenase constructs have been made by gene fusion and chemical crosslinking, but these constructs are hampered with low 
electron transfer efficiency.[18] Higher rates of turnover (Table 1) have been observed for covalently linking $[\mathrm{FeFe}]$-hydrogenase systems via a molecular wire to the $\mathrm{F}_{\mathrm{B}}$ cluster[19] or via gene fusion to ferredoxin.[20] A concern with hydrogenase-based hybrids is that $\mathrm{O}_{2}$ sensitivity will make it difficult to generate $\mathrm{H}_{2}$ at the same time as $\mathrm{O}_{2}$ in future water splitting systems unless $\mathrm{O}_{2}$ evolution and $\mathrm{H}_{2}$ production can be physically divided. Advances in understanding a subclass of $\mathrm{O}_{2}$ tolerant [NiFe]-hydrogenases may extend current PSI $\mathrm{H}_{2}$-based technologies.[17•]

\section{Photosystem I-Platinum Systems}

In 1985 photocatalytic $\mathrm{H}_{2}$ evolution from platinized chloroplasts was first reported.[21] Notably, a recent report demonstrated the extreme durability ( 85 consecutive days of photocatalysis) of a platinized PSI hybrid created by photodeposition of metallic Pt onto PSI isolated from a thermophilic cyanobacterium.[22] A great improvement in rate of $\mathrm{H}_{2}$ production (Table 1) was achieved with a novel PSI bioconjugate design that directly tethers a Pt-nanoparticle via a dithiol molecular wire to a mutated [4Fe-4S] $\mathrm{F}_{\mathrm{B}}$ cluster.[23] Another highly active hybrid is a selfassembled, noncovalent, electrostatically-associated PSI-Pt nanoparticle complex.[24] Importantly, this is the first hybrid to be spectroscopically characterized, providing mechanistic insight into key protein-catalyst interactions and electron transfer reactions related to catalytic function. Although Pt-based systems produce high, sustained photocatalysis rates, future widespread usage will be limited by the scarcity and high cost of precious metals.

\section{Homogeneous Artificial Photosynthetic Systems}

Synthetic transition metal catalysts containing $\mathrm{Co}, \mathrm{Fe}$, and Ni have been extensively studied and provide scalable alternatives to the benchmark $\mathrm{H}_{2}$ evolution catalysts, platinum and hydrogenases. [25-29] The successful use of earth-abundant catalysts in artificial photosynthetic 
systems provides motivation for linking synthetic complexes to PSI chemistry. Multi-molecular homogeneous systems perform photo-induced hydrogen production with freely-diffusing photosensitizer, catalyst, and sacrificial electron donor mixtures. A popular class of catalyst used in these experiments is the cobaloximes; low cost, $\mathrm{O}_{2}$ insensitive, synthetically facile pseudomacrocyclic bis(dimethylglyoxamato) cobalt complexes.[30] Good progress continues in creating suitable earth-abundant catalysts that, when coupled with photosensitizers, exhibit longlived and high catalytic turnover numbers (Figure 2).[31-38] Linked photosensitizer-cobaloxime supramolecular assemblies provide an opportunity to hardwire electron and proton transfer pathways, but, in fact, show poorer $\mathrm{H}_{2}$ generation capabilities than unlinked multi-molecular systems.[39-41] Structure-function studies show that supramolecular structures provide efficient, ultrafast electron transfer to the catalyst from the photosensitizer excited state, but concurrently enable fast charge recombination pathways.[42,43] New linked photosensitizercobaloxime designs are aimed at stabilizing the Co(I) catalytic intermediate state and limiting charge recombination.[44•]

\section{Coupling Nature's Photosynthetic Chemistry with Synthetic Catalytic Function}

Interfacing molecular catalysts with PSI provides the opportunity to create a novel class of biohybrid complexes and gain otherwise unobtainable insight about catalytic function in an aqueous protein environment. Importantly, $\mathrm{H}_{2}$ generation via the catalyst will be tied into the long-lived charge separated state provided by PSI, thus directly addressing the major limitations of uncontrolled or fast back charge recombination reactions encountered in multi- and supramolecular artificial systems. An ongoing synthetic challenge is to discover durable molecular catalysts that are highly active in purely aqueous solution for both electro- and photocatalysis. Embedding catalysts within a protein environment eliminates the artificial 
systems' requirement of organic solvent. The key to creating a functional hybrid system is the effective coupling of rapidly formed single electron photo-excited charge-separated states of PSI to the slower multiple proton-coupled electron transfer reactions at the transition metal catalyst sites. Two successive electrons from PSI must reach the molecular catalyst, thus optimized donor side reactions are required to rapidly re-reduce oxidized donor of PSI, $\mathrm{P} 700^{+}$. Because most systems to date have only looked at half of the water-splitting reaction (herein, proton reduction), sacrificial donors such as sodium ascorbate and electron mediators such as cytochrome $\mathrm{c}_{6}$ are often employed.

Since they have been extensively studied in electro- and photocatalysis, cobaloximes serve as useful starting points for investigating fundamental mechanisms for coupling excited-state RC photochemistry to catalytic bond formation. The PSI-Pt nanoparticle hybrid work established a biomimetic, self-assembly method for coupling PSI to a surface-modified nanoparticle catalyst that did not require covalent linkage for rapid photocatalysis; [24] suggesting that molecular recognition can direct catalysts to the $[4 \mathrm{Fe}-4 \mathrm{~S}]$ cofactor/acceptor side of PSI and establish the geometry necessary for intra-molecular electron transfer. Hybrid protein-molecular catalyst complexes form following stoichiometric addition of a molecular catalyst to buffered protein solution; unbound catalyst is removed by size exclusion methodologies (Figure 3). PSI and the cobaloxime derivative $\mathrm{Co}(\mathrm{dmgH})_{2} \mathrm{pyCl}($ where $\mathrm{dmgH}=$ dimethylgloximate, py = pyridine $)$ readily self-assemble in buffer and the resultant complexes rapidly produce $\mathrm{H}_{2}$ in aqueous solution upon exposure to visible light (Table 1).[45••] The successful generation of $\mathrm{H}_{2}$ from the PSI-cobaloxime hybrid is a clear demonstration of Nature's optimized RC photon capture and charge-separation chemistry driving photocatalysis with observed turnover rates that are faster 
than those reported for related synthetic photosensitizer-cobaloxime complexes[30,46] and that approach the rates observed for the best PSI-Pt nanoparticle (cyt $\mathrm{c}_{6}$ ) system to date.[24]

A related PSI-molecular catalyst hybrid uses a Ni(II) diphosphine catalyst developed by DuBois and coworkers[47] as an efficient electrocatalyst for $\mathrm{H}_{2}$ production.[48] $\left[\mathrm{Ni}\left(\mathrm{P}_{2}{ }^{\mathrm{Ph}} \mathrm{N}_{2}{ }^{\mathrm{Ph}}\right)_{2}\right]\left(\mathrm{BF}_{4}\right)_{2}$ readily binds to native PSI in ratios dependent on the initial amount of $\left[\mathrm{Ni}\left(\mathrm{P}_{2}{ }^{\mathrm{Ph}} \mathrm{N}_{2}{ }^{\mathrm{Ph}}\right)_{2}\right]\left(\mathrm{BF}_{4}\right)_{2}$ added to the protein, similar to $\mathrm{Co}(\mathrm{dmgH})_{2} \mathrm{pyCl}$ complex formation with PSI. Self-assembly of the $\left[\mathrm{Ni}\left(\mathrm{P}_{2}{ }^{\mathrm{Ph}} \mathrm{N}_{2}{ }^{\mathrm{Ph}}\right)_{2}\right]\left(\mathrm{BF}_{4}\right)_{2}$ with isolated PSI resulted in an active photochemical $\mathrm{H}_{2}$-forming biohybrid complex that functions in aqueous solution at near-neutral pH.[49••] (Table 1) Notably, the PSI hybrid generates $\mathrm{H}_{2}$ at a rate two orders of magnitude greater than rates reported for a molecular photosensitizer and $\left[\mathrm{Ni}\left(\mathrm{P}_{2}{ }^{\mathrm{Ph}} \mathrm{N}_{2}{ }^{\mathrm{Ph}}\right)_{2}\right]\left(\mathrm{BF}_{4}\right)_{2}$ system, although this catalyst was quite durable in the artificial system.[31] The protein environment enables photocatalysis in completely aqueous conditions at $\mathrm{pH}$ 6.3, distinct from the strong acid requirement for rapid electrocatalytic and artificial photocatalytic $\mathrm{H}_{2}$ production of $\left[\mathrm{Ni}\left(\mathrm{P}_{2}{ }^{\mathrm{Ph}} \mathrm{N}_{2}{ }^{\mathrm{Ph}}\right)_{2}\right]\left(\mathrm{BF}_{4}\right)_{2}$. [50]

An issue with PSI-molecular catalyst biohybrids is that catalysis is short-lived $(<1.5 \mathrm{~h}$ for $\mathrm{Co}(\mathrm{dmgH})_{2} \mathrm{pyCl} ;<3 \mathrm{~h}$ for $\left.\left[\mathrm{Ni}\left(\mathrm{P}_{2}{ }^{\mathrm{Ph}} \mathrm{N}_{2}{ }^{\mathrm{Ph}}\right)_{2}\right]\left(\mathrm{BF}_{4}\right)_{2}\right)$. Although rapid catalysis is observed immediately after light exposure, the high reactivity quickly tapers off. Degradation of protein is not likely a reason for activity loss, as PSI is functionally robust with activity nearly unchanged after months of continuous testing. [51••] Instability of the molecular catalyst is the most likely issue. Homogeneous artificial systems for light driven hydrogen production have displayed significant problems with photodecomposition of cobaloxime catalysts within a few hours, with ligands sometimes added to the reaction mixture throughout the experiment to prolong catalytic activity.[46] Metal analysis indicates that $>90 \%$ of the molecular catalyst $\left(\mathrm{Co}(\mathrm{dmgH})_{2}\right.$ pyCl or $\left.\left[\mathrm{Ni}\left(\mathrm{P}_{2}{ }^{\mathrm{Ph}} \mathrm{N}_{2}{ }^{\mathrm{Ph}}\right)_{2}\right]\left(\mathrm{BF}_{4}\right)_{2}\right)$ has dissociated from the protein following 
photocatalysis. Whether the catalyst degrades first, then is released from the protein or vice versa is not known. Nevertheless, the high turnover numbers achieved within a short time by biohybrids are promising, and provide a benchmark that can be improved upon with more durable earth abundant molecular catalysts linked to PSI.

\section{Protein Directed Delivery of Catalysts}

Hydrophobic interactions dominate the binding of molecular catalysts to PSI, with the catalyst tucking itself in hydrophobic pockets provided by the large PSI protein matrix ( $350 \mathrm{kDa})$.[9] Thus, different strategies are needed to achieve directed binding of molecular catalysts to PSI. A promising method involves using a catalyst carrying protein to assemble PSI-molecular catalyst hybrids. This method uses inherent protein-protein electrostatic interactions between PSI and its acceptor protein flavodoxin, a small acidic protein that docks to a basic patch provided by PSI

and in close proximity to the $\mathrm{F}_{\mathrm{B}}$ cluster.[52] Controlled incorporation of $\left[\mathrm{Ni}\left(\mathrm{P}_{2}{ }^{\mathrm{Ph}} \mathrm{N}_{2}{ }^{\mathrm{Ph}}\right)_{2}\right]\left(\mathrm{BF}_{4}\right)_{2}$ with the flavodoxin protein was demonstrated by catalyst integration within the native cofactor binding pocket provided by the apo-protein.[49••] Photocatalysis experiments with this modified flavodoxin demonstrated a new mechanism for biohybrid creation that involves protein-directed delivery of a molecular catalyst via apo-flavodoxin to the reducing side of PSI for light-driven catalysis. The rate of photocatalysis nearly doubled and the length of catalysis was extended $30 \%$ compared to catalysis of the directly self-assembled Ni-PSI complex. The catalyst delivery approach provides the potential for self-repair of the biohybrid system with a mechanism for introducing fresh catalyst to the acceptor end of PSI, and studies with the second acceptor protein of PSI, ferredoxin, impart additional experimental possibilities for creating novel solar fuel hybrids.

\section{Concluding Remarks}


The molecular catalyst-protein hybrids overcome the solubility barrier, with the protein bringing the chemistry of the molecular catalysts into aqueous conditions. These systems thus provide the opportunity to understand basic structure-function relationships of non-native inorganic complexes within protein environments. The transition metal sites not only add catalytic function to PSI, but provide direct spectroscopic probes of localized catalyst-protein binding sites and opportunities to monitor intermediates in light-induced catalytic reaction mechanisms using transient EPR and optical spectroscopies. The first spectroscopic data of the Ni(I) sites in PSI and apo-flavodoxin[49••] and the Co(II) site of cobaloxime-substituted apo-myoglobin[53] have been reported. Other related hybrids include heterogeneous bioinorganic systems for photochemical conversion that link proteins with inorganic nanomaterials[54••] and photovoltaic devices. $[51 \bullet \bullet]$

In summary, by interfacing biology and chemistry, novel PSI biohybrids were created that provide a new approach to solar fuels research. Innovative biohybrid designs accomplish practical $\mathrm{O}_{2}$ tolerant, earth abundant photo-generation of $\mathrm{H}_{2}$ by combining Nature's optimized RC light capture and conversion capabilities with the creativity offered by synthetic chemistry. This research is in its early stages. We believe the weak link in current molecular catalyst-hybrid architectures is the chemistry (concerns include $\mathrm{E}_{\mathrm{m}}, \mathrm{pK}_{\mathrm{a}}$, and stability of molecular catalysts) and not the biology, which helps suggest targets towards the development of an optimized system. Opportunities for future hybrid motifs include developing ligand designs that promote interactions, such as electrostatic or covalent, between synthetic molecular catalysts and proteins.[55-57] Another opportunity suggested by the initial steps discussed here is to redirect PSI reducing equivalents to drive catalytic reactions in vivo by genetic modifications.[58••] Reengineered photosynthetic systems may be able to incorporate molecular catalysts in vivo to 
overcome the inherent inefficiencies of photosynthesis and produce practical solar fuel strategies for wide-scale use.

\section{Acknowledgments}

This work is supported by the Division of Chemical Sciences, Geosciences, and Biosciences,

Office of Basic Energy Science of the U.S. Department of Energy under Contract DE-AC02$06 \mathrm{CH} 11357$.

\section{References and recommended reading}

Papers of particular interest, published within the period of review, have been highlighted as:

- of special interest

-• of outstanding interest

1. Lewis NS: Toward cost-effective solar energy use. Science 2007, 315:798-801.

2. Lewis NS, Nocera DG: Powering the planet: Chemical challenges in solar energy utilization. Proc Natl Acad Sci USA 2006, 103:15729-15735.

3. Blankenship RE: Molecular Mechanisms of Photosynthesis. Malden, USA: Blackwell Science Ltd; 2002.

4. Lyons TW, Reinhard CT, Planavsky NJ: The rise of oxygen in Earth's early ocean and atmosphere. Nature 2014, 506:307-315.

5. Deisenhofer J, Epp O, Miki K, Huber R, Michel H: X-Ray Structure-Analysis of a Membrane-Protein Complex - Electron-Density Map at 3Å Resolution and a Model of the Chromophores of the Photosynthetic Reaction Center from Rhodopseudomonas-Viridis. J Mol Biol 1984, 180:385398.

6. Allen JP, Feher G, Yeates TO, Komiya H, Rees DC: Structure of the Reaction Center from RhodobacterSphaeroides R-26 - Protein Cofactor (Quinones and $\mathrm{Fe}^{2+}$ ) Interactions. Proc Natl Acad Sci USA 1988, 85:8487-8491. 
7. Hoff AJ, Deisenhofer J: Photophysics of photosynthesis. Structure and spectroscopy of reaction centers of purple bacteria. Phys Rep 1997, 287:1-247.

8. Umena Y, Kawakami K, Shen JR, Kamiya N: Crystal structure of oxygen-evolving photosystem II at a resolution of 1.9 angstrom. Nature 2011, 473:55-60.

9. Jordan P, Fromme P, Witt HT, Klukas O, Saenger W, Krauss N: Three-dimensional structure of cyanobacterial photosystem I at 2.5 angstrom resolution. Nature 2001, 411:909-917.

10. Blankenship RE, Tiede DM, Barber J, Brudvig GW, Fleming G, Ghirardi M, Gunner MR, Junge W, Kramer DM, Melis A, et al.: Comparing photosynthetic and photovoltaic efficiencies and recognizing the potential for improvement. Science 2011, 332:805-809.

- Review that tackles the difficult challenge of comparing solar energy storage efficiencies of living photosynthetic organisms and photovoltaic devices. Opportunities for enhancing natural photosynthesis to increase solar energy conversion efficiency are discussed.

11. Melis A: Solar energy conversion efficiencies in photosynthesis: Minimizing the chlorophyll antennae to maximize efficiency. Plant Sci 2009, 177:272-280.

12. Dau H, Zaharieva I: Principles, efficiency, and blueprint character of solar-energy conversion in photosynthetic water oxidation. Acc Chem Res 2009, 42:1861-1870.

13. Zhu XG, Long SP, Ort DR: Improving photosynthetic efficiency for greater yield. Annu Rev Plant Biol 2010, 61:235-261.

14. Lubner CE, Grimme RA, Bryant DA, Golbeck JH: Wiring photosystem I for direct hydrogen production. Biochemistry 2010, 49:404-414.

15. Fontecilla-Camps JC, Amara P, Cavazza C, Nicolet Y, Volbeda A: Structure-function relationships of anaerobic gas-processing metalloenzymes. Nature 2009, 460:814-822.

16. Mulder DW, Shepard EM, Meuser JE, Joshi N, King PW, Posewitz MC, Broderick JB, Peters JW: Insights into [FeFe]-Hydrogenase Structure, Mechanism, and Maturation. Structure 2011, 19:1038-1052.

17. Friedrich B, Fritsch J, Lenz O: Oxygen-tolerant hydrogenases in hydrogen-based technologies. Curr Opin Biotechnol 2011, 22:358-364.

- Review of [NiFe]-hydrogenases that produce $\mathrm{H}_{2}$ in the presence of $\mathrm{O}_{2}$ and discussion of constructing microbial $\mathrm{H}_{2}$-producing cells.

18. Ihara M, Nishihara H, Yoon KS, Lenz O, Friedrich B, Nakamoto H, Kojima K, Honma D, Kamachi T, Okura I: Light-driven hydrogen production by a hybrid complex of [NiFe]-hydrogenase and the cyanobacterial photosystem I. Photochem Photobio 2006, 82:676-682.

19. Lubner CE, Applegate AM, Knorzer P, Ganago A, Bryant DA, Happe T, Golbeck JH: Solar hydrogenproducing bionanodevice outperforms natural photosynthesis. Proc Natl Acad Sci USA 2011, 108:20988-20991. 
20. Yacoby I, Pochekailov S, Toporik H, Ghirardi ML, King PW, Zhang SG: Photosynthetic electron partitioning between [FeFe]-hydrogenase and ferredoxin:NADP ${ }^{+}$-oxidoreductase (FNR) enzymes in vitro. Proc Natl Acad Sci USA 2011, 108:9396-9401.

21. Greenbaum E: Platinized chloroplast: A novel photocatalytic material. Science 1985, 230:13731375.

22. Iwuchukwu IJ, Vaughn M, Myers N, O'Neill H, Frymier P, Bruce BD: Self-organized photosynthetic nanoparticle for cell-free hydrogen production. Nat Nanotechnol 2010, 5:73-79.

23. Grimme RA, Lubner CE, Bryant DA, Golbeck JH: Photosystem I/molecular wire/metal nanoparticle bioconjugates for the photocatalytic production of $\mathbf{H}_{2}$. J Am Chem Soc 2008, 130:6308-6309.

24. Utschig LM, Dimitrijevic NM, Poluektov OG, Chemerisov SD, Mulfort KL, Tiede DM: Photocatalytic hydrogen production from noncovalent biohybrid Photosystem I/Pt nanoparticle complexes. J Phys Chem Lett 2011, 2:236-241.

25. Bullock RM, Appel AM, Helm ML: Production of hydrogen by electrocatalysis: making the $\mathbf{H}-\mathbf{H}$ bond by combining protons and hydrides. Chem Commun 2014, 50:3125-3143.

26. Du PW, Eisenberg R: Catalysts made of earth-abundant elements (Co, Ni, Fe) for water splitting: Recent progress and future challenges. Energy Environ Sci 2012, 5:6012-6021.

27. DuBois DL: Development of molecular electrocatalysts for energy storage. Inorg Chem 2014, 53:3935-3960.

28. McKone JR, Marinescu SC, Brunschwig BS, Winkler JR, Gray HB: Earth-abundant hydrogen evolution electrocatalysts. Chem Sci 2014, 5:865-878.

29. Thoi VS, Sun YJ, Long JR, Chang CJ: Complexes of earth-abundant metals for catalytic electrochemical hydrogen generation under aqueous conditions. Chem Soc Rev 2013, 42:23882400.

30. Dempsey JL, Brunschwig BS, Winkler JR, Gray HB: Hydrogen evolution catalyzed by cobaloximes. Acc Chem Res 2009, 42:1995-2004.

31. McLaughlin MP, McCormick TM, Eisenberg R, Holland PL: A stable molecular nickel catalyst for the homogeneous photogeneration of hydrogen in aqueous solution. Chem Commun 2011, 47:7989-7991.

32. Han ZJ, Shen LX, Brennessel WW, Holland PL, Eisenberg R: Nickel pyridinethiolate complexes as catalysts for the light-driven production of hydrogen from aqueous solutions in noble-metalfree systems. J Am Chem Soc 2013, 135:14659-14669.

33. Sun YJ, Sun JW, Long JR, Yang PD, Chang CJ: Photocatalytic generation of hydrogen from water using a cobalt pentapyridine complex in combination with molecular and semiconductor nanowire photosensitizers. Chem Sci 2013, 4:118-124. 
34. Singh WM, Baine T, Kudo S, Tian SL, Ma XAN, Zhou HY, DeYonker NJ, Pham TC, Bollinger JC, Baker DL, et al.: Electrocatalytic and photocatalytic hydrogen production in aqueous solution by a molecular cobalt complex. Angew Chem Int Ed 2012, 51:5941-5944.

35. McNamara WR, Han ZJ, Yin CJ, Brennessel WW, Holland PL, Eisenberg R: Cobalt-dithiolene complexes for the photocatalytic and electrocatalytic reduction of protons in aqueous solutions. Proc Natl Acad Sci USA 2012, 109:15594-15599.

36. Gross MA, Reynal A, Durrant JR, Reisner E: Versatile photocatalytic systems for $\mathbf{H}_{\mathbf{2}}$ generation in water based on an efficient DuBois-type nickel catalyst. J Am Chem Soc 2014, 136:356-366.

37. Khnayzer RS, Thoi VS, Nippe M, King AE, Jurss JW, El Roz KA, Long JR, Chang CJ, Castellano FN: Towards a comprehensive understanding of visible-light photogeneration of hydrogen from water using cobalt(II) polypyridyl catalysts. Energy Environ Sci 2014, 7:1477-1488.

38. Dutta A, Lense $S$, Hou J, Engelhard MH, Roberts JAS, Shaw WJ: Minimal proton channel enables $\mathbf{H}_{\mathbf{2}}$ oxidation and production with a water-soluble nickel-based catalyst. J Am Chem Soc 2013, 135:18490-18496.

39. Fihri A, Artero V, Razavet M, Baffert C, Leibl W, Fontecave M: Cobaloxime-based photocatalytic devices for hydrogen production. Angew Chem Int Ed 2008, 47:564-567.

40. McCormick TM, Han ZJ, Weinberg DJ, Brennessel WW, Holland PL, Eisenberg R: Impact of ligand exchange in hydrogen production from cobaloxime containing photocatalytic systems. Inorg Chem 2011, 50:10660-10666.

41. Zhang $P$, Jacques PA, Chavarot-Kerlidou M, Wang M, Sun LC, Fontecave M, Artero V: Phosphine coordination to a cobalt diimine-dioxime catalyst increases stability during light-driven $\mathbf{H}_{2}$ production. Inorg Chem 2012, 51:2115-2120.

42. Mulfort KL, Mukherjee A, Kokhan O, Du PW, Tiede DM: Structure-function analyses of solar fuels catalysts using in situ X-ray scattering. Chem Soc Rev 2013, 42:2215-2227.

43. Mulfort KL, Tiede DM: Supramolecular cobaloxime assemblies for $\mathbf{H}_{\mathbf{2}}$ photocatalysis: an initial solution state structure-function analysis. J Phys Chem B 2010, 114:14572-14581.

44. Mukherjee A, Kokhan O, Huang J, Niklas J, Chen LX, Tiede DM, Mulfort KL: Detection of a chargeseparated catalyst precursor state in a linked photosensitizer-catalyst assembly. Phys Chem Chem Phys 2013, 15:21070-21076.

- Direct observation of a transient Co(I) state in a homogeneous supramolecular system.

45. Utschig LM, Silver SC, Mulfort KL, Tiede DM: Nature-driven photochemistry for catalytic solar hydrogen production: A Photosystem I-transition metal catalyst hybrid. J Am Chem Soc 2011, 133:16334-16337.

-• First demonstration of a solar fuel hybrid that utilizes PSI's optimized photochemistry to drive $\mathrm{H}_{2}$ production from a molecular catalyst. This PSI-cobaloxime system provides a benchmark for creation of future PSI-molecular catalyst hybrids. 
46. McCormick TM, Calitree BD, Orchard A, Kraut ND, Bright FV, Detty MR, Eisenberg R: Reductive side of water splitting in artificial photosynthesis: New homogeneous photosystems of great activity and mechanistic insight. J Am Chem Soc 2010, 132:15480-15483.

47. Rakowski DuBois $\mathrm{M}$, DuBois DL: Development of molecular electrocatalysts for $\mathrm{CO}_{2}$ reduction and $\mathbf{H}_{\mathbf{2}}$ production/oxidation. Acc Chem Res 2009, 42:1974-1982.

48. Wilson AD, Newell RH, McNevin MJ, Muckerman JT, Rakowski DuBois M, DuBois DL: Hydrogen oxidation and production using nickel-based molecular catalysts with positioned proton relays. J Am Chem Soc 2006, 128:358-366.

49. Silver SC, Niklas J, Du PW, Poluektov OG, Tiede DM, Utschig LM: Protein delivery of a Ni catalyst to photosystem I for light-driven hydrogen production. J Am Chem Soc 2013, 135:13246-13249.

- First example of a PSI hybrid incorporating a synthetic molecular nickel catalyst for photocatalytic hydrogen evolution. First report of insertion of a molecular catalyst within the native-cofactor binding pocket of a flavodoxin protein. Demonstration of a novel strategy for the creation of solar fuel hybrids that involves delivery of a molecular catalyst via apo-flavodoxin to the reducing end of PSI for light-driven catalysis.

50. Wilson AD, Shoemaker RK, Miedaner A, Muckerman JT, DuBois DL, Rakowski DuBois M: Nature of hydrogen interactions with $\mathrm{Ni}(\mathrm{II})$ complexes containing cyclic phosphine ligands with pendant nitrogen bases. Proc Natl Acad Sci USA 2007, 104:6951-6956.

51. Nguyen K, Bruce BD: Growing green electricity: Progress and strategies for use of Photosystem I for sustainable photovoltaic energy conversion. Biochim Biophys Acta 2014, 1837:1553-1566.

$\bullet$ Review of recent advances in the utilization of PSI for photovoltaic devices.

52. Medina M: Structural and mechanistic aspects of flavoproteins: photosynthetic electron transfer from photosystem I to NADP(+). FEBS J 2009, 276:3942-3958.

53. Bacchi M, Berggren G, Niklas J, Veinberg E, Mara MW, Shelby ML, Poluektov OG, Chen LX, Tiede DM, Cavazza C, et al.: Cobaloxime-based artificial hydrogenases. Inorg Chem 2014, 53:8071-8082.

54. King PW: Designing interfaces of hydrogenase-nanomaterial hybrids for efficient solar conversion. Biochim Biophys Acta 2013, 1827:949-957.

-• Review of enzyme-based hybrid systems and devices that couple biological catalysis with semiconductor nanomaterials. A nice discussion of design features that tune molecular interfaces for controlling molecular assembly, electron-transfer and photocatalysis.

55. Sano Y, Onoda A, Hayashi T: A hydrogenase model system based on the sequence of cytochrome c: photochemical hydrogen evolution in aqueous media. Chem Commun 2011, 47:8229-8231.

56. Sano Y, Onoda A, Hayashi T: Photocatalytic hydrogen evolution by a diiron hydrogenase model based on a peptide fragment of cytochrome $c(556)$ with an attached diiron carbonyl cluster and an attached ruthenium photosensitizer. J Inorg Biochem 2012, 108:159-162. 
57. Roy A, Madden C, Ghirlanda G: Photo-induced hydrogen production in a helical peptide incorporating a [FeFe] hydrogenase active site mimic. Chem Commun 2012, 48:9816-9818.

58. Lassen LM, Nielsen AZ, Ziersen B, Gnanasekaran T, Møller BL, Jensen PE: Redirecting photosynthetic electron flow into light-driven synthesis of alternative products including high-value bioactive natural compounds. ACS Synth Biol 2013, 3:1-12.

-• Review of coupling P450 enzymes to photosynthesis in vivo and PSI in vitro for the synthesis of bioactive natural compounds. 
Figure 1. Photosystem I-catalyst hybrid systems for light-driven $\mathrm{H}_{2}$ production. The center panel depicts a diagram of the overall photocatalytic scheme of $\mathrm{H}_{2}$ production from Photosystem I-catalyst systems wherein a photogenerated electron from PSI is transferred to a bound catalyst. The catalyst must accept two successive photogenerated electrons from PSI to generate one $\mathrm{H}_{2}$ molecule. Electron donors, plastocyanin or cytochrome $c_{6}$ in the presence of excess sodium ascorbate, reduce the photon-oxidized primary donor of PSI. This is necessary for rapid turnovers of PSI that enable multi-electron transfer to the catalyst site(s) for $\mathrm{H}_{2}$ production. Outer groupings include three types of catalysts that have been successfully incorporated with PSI's photochemistry to make functional $\mathrm{H}_{2}$-producing hybrids. Earth-abundant molecular catalysts include cobaloxime,[45••] Ni diphosphine,[49••] and Ni-apoflavodoxin.[49••] Examples of noble metal catalysts include Pt nanoparticles bound to PSI via electrostatic binding, [24] Pt nanoparticles linked via 1,6-hexanedithiol to the $\mathrm{F}_{\mathrm{B}}$ cluster of PSI, [23] and Pt nanoclusters formed by photodeposition onto PSI.[22] The last grouping highlights some PSIhydrogenase hybrids including a cyt c-PSI linked to a [FeFe]-hydrogenase by octanedithiol, [19] an [FeFe]-hydrogenase:ferredoxin fusion protein, [20] and [NiFe]- hydrogenase genetically fused to PSI. [18]

Figure 2. Structures of molecular catalysts for $\mathrm{H}_{2}$ production. Cobalt catalysts are shown the green box. On the left is the cobaloxime linked to PSI (1) [45••] and in supramolecular complexes (2).[39] The right side illustrates variations of pentadentate nitrogen-Co catalysts used in synthetic systems for photocatalysis (3-5) [33,34,37] which are suggested to be more robust and water soluble. The bottom panel shows a Co dithiolene catalyst (6) which can perform rapid catalysis in acetonitrile-water mixtures.[35] In the blue box nickel catalysts are shown. Extensive variations on nickel diphosphine catalysts have been developed to increase the 
solubility and functionality in aqueous solution (7-9).[31,36,38] Catalyst (7) has been linked to PSI and Ni-apoflavodoxin for $\mathrm{H}_{2}$ production.[49••] Catalyst (10) shows a nickel pyridine thiolate catalyst intended to mimic the [NiFe]-hydrogenase active site.[32] The purple box shows an iron containing catalyst intended to mimic the [FeFe]-hydrogenase active site which has been appended into a peptide photocatalytic system (11). [57]

Figure 3. Preparation of Photosystem I-molecular catalyst hybrids. Dark-adapted PSI ( $5 \mu \mathrm{M}$ PSI monomer in a buffer $\mathrm{pH} 7.8$ - 8.0) is incubated with 2-10 mole equivalents of molecular catalyst (diluted from a $5 \mathrm{mM}$ catalyst stock solution prepared in DMSO). The PSI and molecular catalyst are incubated for $2 \mathrm{~h}$ at room temperature in the dark to allow complex formation. Unbound catalyst is removed from PSI-catalyst complexes by size exclusion filtration (50000 MWCO devices) or chromatography followed by several washing steps. Metal analysis is used to determine the amount of catalyst bound to PSI. For the photocatalysis experiment, a reaction mixture containing $80 \mathrm{nM}$ PSI-catalyst hybrid, $100 \mathrm{mM}$ sodium ascorbate (sacrificial electron donor), and $4-8 \mu \mathrm{M}$ cytochrome $\mathrm{c}_{6}$ (electron mediator) is illuminated with a xenon lamp. $\mathrm{H}_{2}$ bubbles produced during illumination of a PSI-cobaloxime hybrid solution are shown.[45••] The amount of $\mathrm{H}_{2}$ generated is determined by sampling and analyzing the headspace every 10 - 30 min for $\mathrm{H}_{2}$ by gas chromatography. 


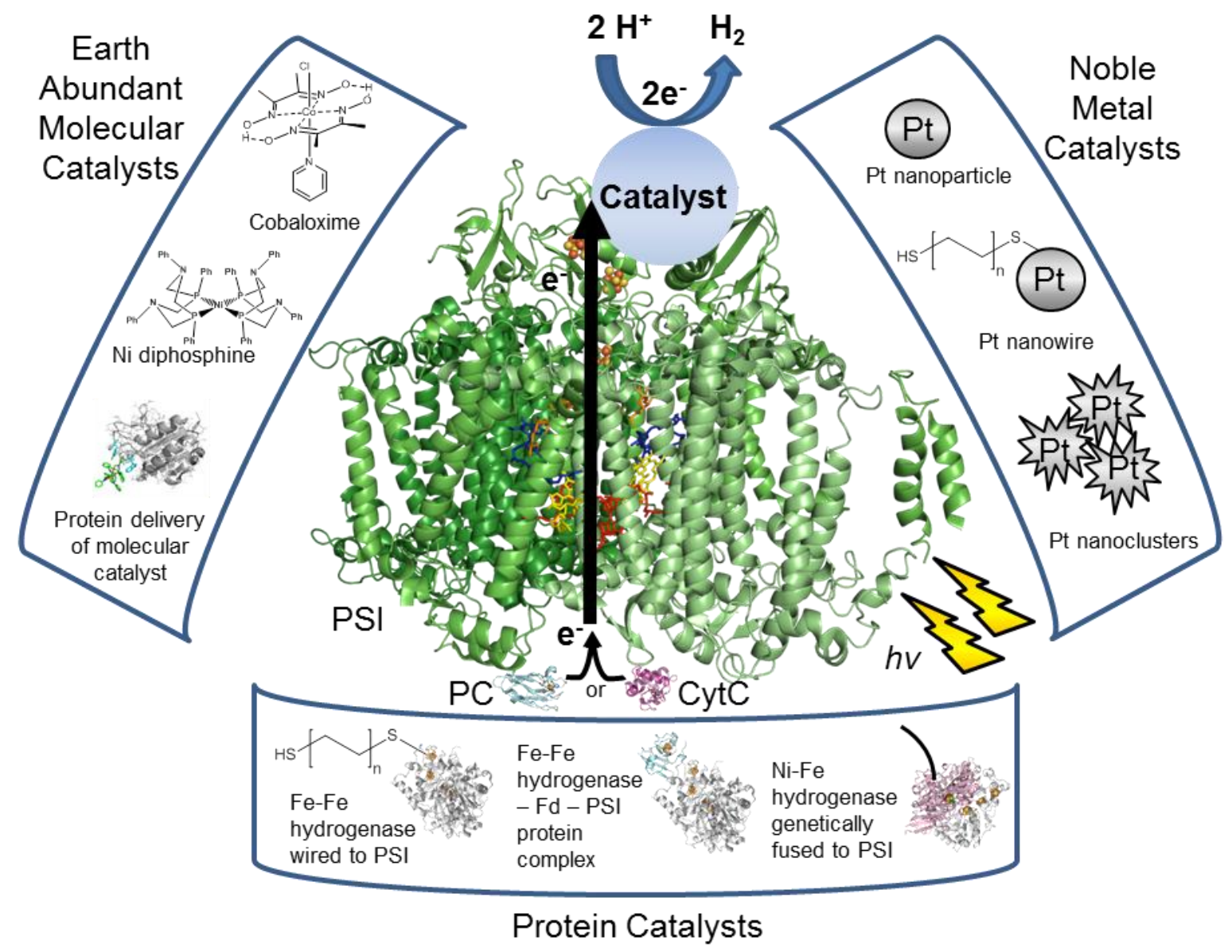

Figure 1 


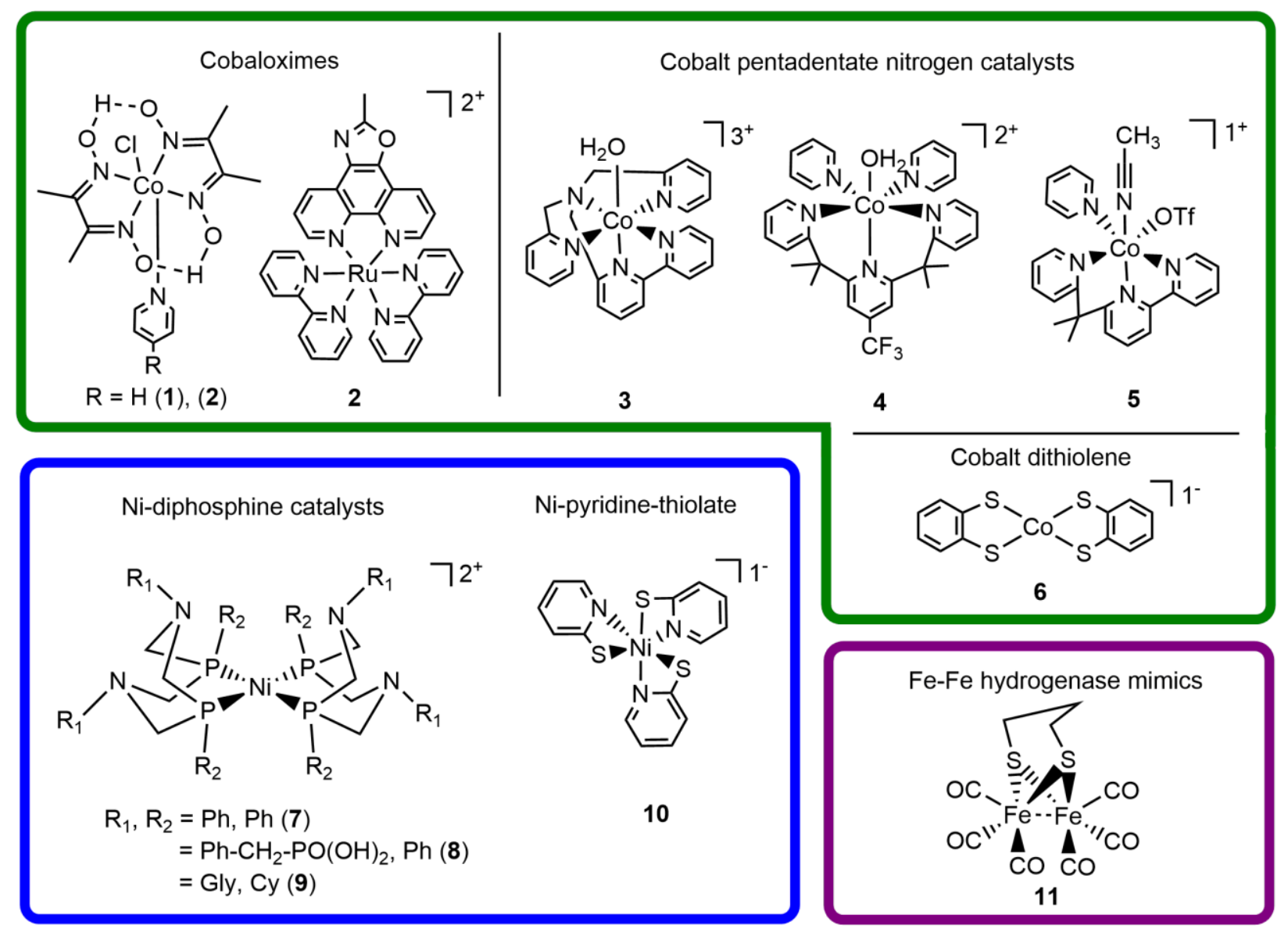

Figure 2. 

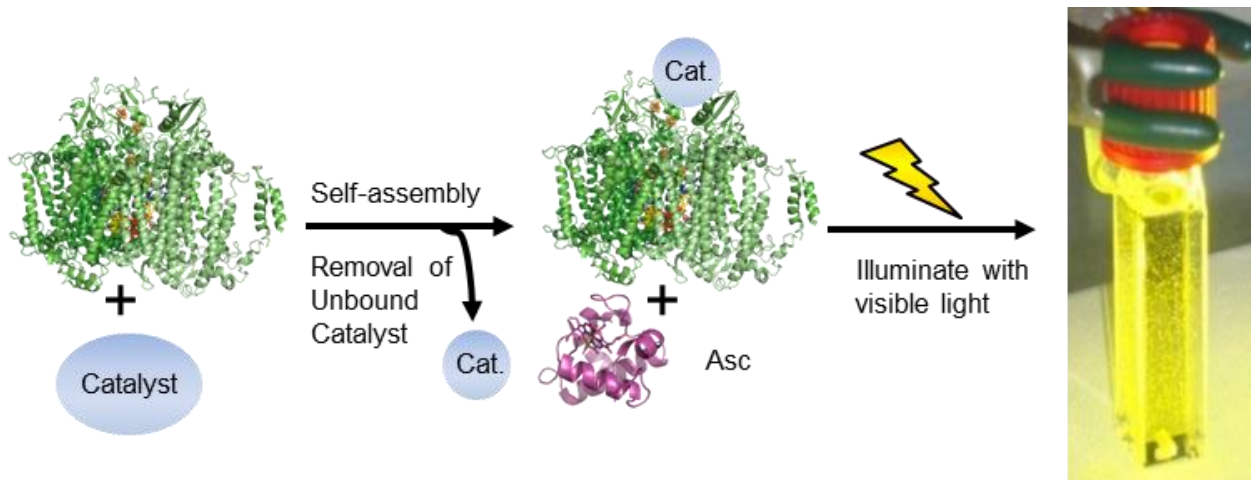

Figure 3. 
Table 1. Rates of light-driven hydrogen production and turnover numbers for PSI-Catalyst hybrid systems

$\begin{array}{ccc}\text { PSI-Catalyst System } & \begin{array}{c}\text { Rate of } \mathrm{H}_{2} \text { Production } \\ {\left[\mathrm{mol} \mathrm{H}_{2}\left(\mathrm{~mol} \mathrm{PSI}^{-1} \mathrm{~s}^{-1}\right]\right.}\end{array} & \text { TON (time) }\end{array}$

\begin{tabular}{|c|c|c|}
\hline PSI-nanoclusters photoprecipitated, long-lived ${ }^{\text {a, }[22]}$ & 0.002 & $\mathrm{nd}^{*}(2000 \mathrm{~h})$ \\
\hline PSI-[NiFe]-hydrogenase, genetic fusion ${ }^{[18]}$ & 0.01 & $n d^{*}(3 \mathrm{~h})$ \\
\hline PSI-nanoclusters photoprecipitated, short-lived ${ }^{\mathrm{a},[22]}$ & 0.13 & $\mathrm{nd}^{*}(2 \mathrm{~h})$ \\
\hline PSI-[FeFe]-hydrogenase-PetF in vitro complex ${ }^{\mathrm{b},[20]}$ & 0.31 & $\mathrm{nd}^{*}(0.5 \mathrm{~h})$ \\
\hline PSI-Ni diphosphine ${ }^{\mathrm{a},[49]}$ & 0.73 & $1870(3 \mathrm{~h})$ \\
\hline PSI-[FeFe]-hydrogenase-Fd protein complex ${ }^{\mathrm{b},[20]}$ & 1.07 & $\mathrm{nd}^{*}(1 \mathrm{~h})$ \\
\hline PSI-molecular wire-Pt nanoparticle ${ }^{\mathrm{a},[23]}$ & 1.17 & $4210(12 \mathrm{~h})$ \\
\hline PSI-NiApoFld protein delivery ${ }^{\mathrm{a}, ~[49]}$ & 1.25 & $2825(4 \mathrm{~h})$ \\
\hline PSI-cobaloxime ${ }^{a,[45]}$ & 2.83 & $5900(1.5 \mathrm{~h})$ \\
\hline PSI-Pt nanoparticle ${ }^{\mathrm{a},[24]}$ & 5.83 & $80000(4 \mathrm{~h})$ \\
\hline $\begin{array}{l}\text { PSI-molecular wire-[FeFe]-hydrogenase }{ }^{\mathrm{a},}[19] \\
{ }^{*}{ }^{n} \text { d, not determined, redox mediators: }{ }^{a} \text { Cyt } c_{6},{ }^{b} P C\end{array}$ & 52.4 & $n d^{*}(3 \mathrm{~h})$ \\
\hline
\end{tabular}

